\title{
Mulheres Homossexuais e as Relações Vividas na Escola: Entre visibilidades e invisibilidades
}

\author{
Homosexual Women and Relationships Lived at the School: Between visibility \\ and invisibility
}

\author{
Patricia Magri Granúzzio \\ Universidade Metodista de Piracicaba \\ pmgranuzzio@yahoo.com.br
}

\section{Resumo}

Objetivando participar das discussões em relação à homossexualidade, este trabalho apresenta uma pesquisa realizada para compreender quais são os sentidos atribuídos por sujeitos homossexuais às relações sociais vividas na escola. Um breve panorama sobre homossexualidade e as imagens construídas no mundo e no Brasil são apresentadas e um pequeno histórico dos conceitos de normalidade e anormalidade nos discursos médico, religioso e educacional é traçado.

Palavras - chave: Mulheres; homossexualidade; escola; relações de gênero.

\begin{abstract}
Aiming to participate in the discussions about homosexuality, this paper presents a study conducted to understand what are the meanings attributed by subjects to homosexual relationships experienced in school. A brief overview of homosexuality and the images constructed both in the world and in Brazil are presented and a brief history of the concepts of normality and abnormality in medical, religious and educational discourses is plotted.
\end{abstract}

Keywords: Women, homosexuality; school; gender relations. 


\section{Introdução}

Desde muito tempo afirmou-se que a escola brasileira era uma instituição educacional laica em relação à religiosidade e neutra em relação à sexualidade, porém, por meio de simples análises vemos que essa laicidade e neutralidade nunca existiram. A formação de professores (as) e a prática que deles (as) se esperava enfatizou sempre uma conduta cristã e um caráter assexuado; quando não assexuado, os conhecimentos e práticas estavam meramente relacionados ao sistema reprodutivo dos heterossexuais.

Michel Foucault (1988) esclarece que existem apenas dois modos de se produzir e adquirir a verdade sobre o sexo. Seriam eles a ars erótica e a scientia sexualis. A arte erótica estaria ligada a uma verdade extraída do próprio prazer e este deveria ser encarado como prática e experiência, não estando relacionado a leis, permissões ou proibições. Segundo esse autor, nossa civilização não possui a ars erótica, mas desenvolveu procedimentos que se ordenam para dizer a verdade do sexo, seria a scientia sexualis, dominada pelo discurso científico e pela preocupação com a reprodução sadia. Falar de sexualidade é, de acordo com Foucault, seguir três eixos que a constituem: a formação dos saberes que a ela se referem, os sistemas de poder que regulam sua prática e as formas pelas quais os indivíduos podem e devem se reconhecer como sujeitos dessa sexualidade. Foucault (1988), em sua História da Sexualidade, afirma que ainda hoje vivemos num mundo em que nossa sexualidade é contida, muda e hipócrita.

Seguindo as ideias de Foucault, Camargo e Ribeiro (1999) afirmam que falar sobre sexo com crianças, adolescentes, homens, mulheres constitui-se hoje uma forma de controle de comportamento. Uma das mais poderosas formas de controle da sexualidade humana diz respeito aos homossexuais.

A palavra homossexual foi criada em 1869, o húngaro Károly Maria Kertbeny (nascido Karl Maria Benkert) ${ }^{1}$ criou um híbrido linguístico, meio grego, meio latino. Homo, do grego, significando 'igual' e sexus, do latim, 'sexo'. O termo homossexual é usado para definir sentimentos ou comportamentos de pessoas que estão ligadas emocionalmente ou se sentem sexualmente atraídas por pessoas do mesmo sexo.

No Brasil, a palavra 'homossexualidade' ganha cada vez mais espaço e o termo 'homossexualismo' deixa, pouco a pouco, de ser usado. O sufixo 'ismo' daria a ideia de doença, patologia, constituindo uma forma de pensamento antiquado e preconceituoso. A denominação e utilização da palavra homossexualidade têm uma forte discussão em relação ao seu significado e a sua utilização nos dias atuais, alguns estudiosos e integrantes de organizações não governamentais e grupos de discussão defendem outras formas de referência a pessoas com sexualidades diferenciadas da estabelecida e aceita socialmente, como, por exemplo, a palavra homocultura. A palavra homocultura ainda não está dicionarizada. A palavra é um hibridismo, formada pelo antepositivo grego homo- (que significa 'mesmo, semelhante, igual'), anteposto à palavra de origem latina cultura, significando, assim, cultura do mesmo ou do semelhante.

Até o século XVIII, a homossexualidade era considerada errada porque era vista como algo não natural e que fugia aos ensinamentos religiosos, entretanto, na segunda metade do século XIX a temática passou a ocupar os discursos de médicos e de psiquiatras e a eles passou a pertencer à verdade sobre o sexo.

No Brasil, a questão da sexualidade e mais especificamente da homossexualidade foi durante muito tempo silenciada pelo regime militar ditatorial. Somente com o processo de abertura política é que as primeiras publicações de organizações com integrantes homossexuais que buscavam aliança com outras minorias começaram a abordar a homossexualidade nos seus aspectos políticos, existenciais e culturais. Entretanto, acusados de contrariar a 'moral e os bons costumes' muitos foram processados (FRY e MACRAE, 1985, p.21).

Em 1978, o Brasil viu surgir mais sistematicamente e de modo mais organizado diversos movimentos sociais que lutavam por direitos humanos, dentre eles o Movimento Negro Unificado, o Movimento Feminista e os primeiros núcleos de artistas, intelectuais e profissionais liberais que protestavam contra a maneira com que os homossexuais eram vistos e tratados no nosso país. Os movimentos sociais precisaram aguardar a abertura política total para poderem se constituir oficialmente, mas desde a década de 1960 a academia brasileira já tinha alguns pesquisadores que se interessavam pela homossexualidade. Barbosa da Silva (1960), quando cursava especialização em sociologia na USP escreveu sobre a sociabilidade dos homossexuais paulistanos.

Houve escritos brasileiros anteriores a essa pesquisa, como a obra de Edmur de Aguiar Whitaker, em 1939 e a de Sílvio Marone, em 1947, porém, apresentavam posturas moralistas e viam a homossexualidade como uma patologia. A inovação que Barbosa da Silva apresenta em sua monografia de 1958 é pensar os homossexuais como mais um grupo social da cidade de São Paulo, não se tratava de pessoas doentes, perversas ou com defeitos genéticos

Patricia Magri Granúzzio 
ou hormonais, tratava-se de pessoas apenas. Mesmo com uma pesquisa inovadora, Barbosa da Silva saiu do país por questões políticas e sua obra só foi tornada pública após 45 anos.

Com o final do regime autoritário, deu-se no Brasil uma crescente visibilidade pública da homossexualidade, houve tanto mudanças no papel social da pessoa homossexual quanto em sua militância política. Entretanto, essa visibilidade não apresentou apenas aspectos positivos. Durante muito tempo, e até mesmo hoje em dia, a mídia brasileira tratou o homossexual de modo caricato, sempre ridicularizando seus gestos - a 'bicha alegre e espalhafatosa' ou a 'mulher borracheira e motorista de caminhão', reforçando a imagem de que o homossexual é um indivíduo movido a prazeres físicos, não explorando os aspectos psicológicos e, o mais grave de tudo, relacionou a figura do homossexual masculino a crimes sexuais, como a pedofilia. Uma das imagens mais negativas que rompeu com a invisibilidade e o silêncio sobre a homossexualidade foi associar a pessoa homossexual ao surgimento e transmissão do vírus da AIDS, fato que interfere ainda hoje quando o assunto é a sexualidade.

Desde seu surgimento, na década de 1980, toda e qualquer publicidade governamental em torno da AIDS tem como foco principal a prevenção de heterossexuais. Desde 1985, o Conselho Federal de Medicina no Brasil (CFM) considerou sem efeito o parágrafo 302.0 do Código Internacional de Doenças (CID) da Organização Mundial de Saúde (OMS) que, desde 1948, catalogava o 'homossexualismo' como desvio e transtorno sexual. Em 1991, a Anistia Internacional passou a considerar violação dos direitos humanos a proibição da prática homossexual. Em 23 de março de 1999, o Conselho Federal de Psicologia no Brasil (CFP) aprovou a Resolução CFP n ${ }^{0}$ 001/99 que "Estabelece normas de atuação para os psicólogos em relação à questão da Orientação Sexual", recomendando que ninguém deve ser submetido a qualquer "tratamento de cura por desejar e/ou se relacionar com pessoas do mesmo sexo".

Atualmente, a homossexualidade não é mais considerada pela medicina e pela psicologia como uma patologia e sim como um comportamento sexual natural e um estilo de conduta. A Organização Mundial de Saúde (OMS), em 1991 e 1993, ao fazer a revisão e publicação da $10^{\mathrm{a}}$ edição da Classificação Internacional de Doenças (CID 10), deixou de considerar a homossexualidade como uma doença mental. Entretanto, as lutas pela visibilidade continuam, não significando apenas ser visto, mas sim como uma ação política que envolve tomada de consciência, resistência à opressão.

\section{Objetivos}

O objetivo deste artigo é apresentar alguns dos sentidos produzidos sobre as relações sociais envolvendo escola e mulheres autodeclaradas homossexuais.

A relação escola e educação sexual no Brasil sempre foi marcada por avanços e retrocessos. No início do século XX predominaram as ideias médicohigienistas e o que se entendia como educação sexual nada mais era do que o combate à masturbação e às doenças venéreas, além de prescrições para que as mulheres exercessem adequadamente o papel de esposa e mãe.

Segundo Abramovay, Castro \& Silva (2004), já na década de 1920, a educação sexual era defendida por feministas como Berta Lutz que reivindicavam proteção à infância e à maternidade. Em 1928, o Congresso Nacional aprovou proposta de educação sexual nas escolas, mas, até os anos 50, houve perseguições pela mídia e processos judiciais contra aqueles que defendiam a educação sexual nas escolas; a Igreja Católica era uma das grandes opositoras a essa ideia. Na década de 1960, algumas experiências isoladas iriam acontecer em algumas escolas no Rio de Janeiro, Minas Gerais e São Paulo, apesar das perseguições. Apenas nos anos 1970 é que os debates ressurgiriam com mais intensidade, resultando em projetos legislativos, muitos dos quais foram rejeitados. De acordo com Altmann (2001), em 1970, a Comissão Nacional de Moral e Civismo iniciou um discurso que faria com que, em 1976, o tema ficasse no âmbito familiar, as escolas teriam a opção de trabalhar ou não.

Uma Lei importante para a educação, ainda que numa concepção biologizante, foi promulgada em 1971, fixando as Diretrizes e Bases para o Ensino de 1o e 2o graus - Lei 5.692. Essa Lei tornou obrigatória a inclusão de Programas de Saúde no currículo escolar. Mesmo estando ligada diretamente a programas de saúde, tal Lei possibilitou, anos mais tarde, a inserção de algumas reflexões sobre sexualidade humana no momento em que esta discussão ainda não era oficialmente permitida na rede escolar.

Em 1978, aconteceu em São Paulo o $1^{\circ}$ Congresso Nacional sobre Educação Sexual nas Escolas. Reconhecendo-se desqualificados para a implantação da discussão sobre sexualidade humana nas escolas, os professores admitiram a impossibilidade de tal ação.

Com a epidemia da AIDS, nos anos 1980, várias experiências começariam a surgir ao lado de trabalhos e projetos cujo alvo era os adolescentes e os casos de gravidez, preocupação que até hoje ocupa boa parte dos projetos escolares. 
Silva (2004, p. 29) afirma que a partir de 1988 entrou em vigor uma nova Proposta Curricular de Ciências da Secretaria de Estado da Educação do Governo de São Paulo. Esse documento propunha a inclusão de questões referentes à saúde integradas às explicações científicas e noções de sexualidade humana. De acordo com a autora, apesar do grande avanço trazido pela proposta curricular, mais uma vez houve a preocupação quanto à viabilização da proposta, uma vez que os professores não tinham sido formados para tal abordagem. Em 1989, os Ministérios da Educação e da Saúde apoiaram cursos para capacitação de educadores em conteúdos de sexualidade humana, implantados em vários estados nordestinos. Em 1992, devido ao crescente aumento dos casos de pessoas contaminadas com o vírus da AIDS, o governo federal recomendou a implantação, manutenção e ampliação de projetos educativos de prevenção à AIDS nas redes oficiais e privadas de ensino.

Os homossexuais e transgêneros foram sempre vistos como potenciais portadores do vírus HIV, deixando claro que a preocupação é proteger os heterossexuais do vírus, em nenhuma das propagandas há/houve a preocupação em proteger os homossexuais e os transgêneros dos heterossexuais e de seus prováveis vírus. Foi criado o mito de que quem tem AIDS, ou melhor, quem contamina os heterossexuais, são os homossexuais e os transgêneros, isso é uma construção social e histórica, no início o vírus foi associado à imagem do homossexual como uma peste e o serviço público de saúde lutava/prezava pela saúde dos heterossexuais. Hoje muita coisa está mudando.

Em 1993, o Ministério da Educação e Cultura (MEC) criou o Conselho Nacional de Projetos Especiais (CONAPES), que previa a normatização da Educação Sexual no sistema público de ensino. Em 1994, o MEC distribui uma adaptação/versão do Guia de Orientação Sexual, publicação estadunidense cujos conteúdos sobre Educação Sexual tinham uma visão multidisciplinar da sexualidade ${ }^{2}$.

A partir de 1997, o Governo Federal estabeleceu o ensino da orientação sexual incorporando-a como um tema transversal constante nos Parâmetros Curriculares para o Ensino Fundamental (PCN), ao lado dos demais temas a serem articulados com as diversas disciplinas do currículo oficial ${ }^{3}$. Nos volumes que se referem a Ciências Naturais ou Orientação Sexual, o tema da sexualidade humana é tratado de um ponto de vista quase que exclusivamente heterossexual. De acordo com os PCN, a discussão sobre a sexualidade seguiria três eixos principais: 'Corpo: matriz da sexualidade'; 'Relações de gênero'; Prevenção de doenças sexualmente transmissíveis/AIDS (BRASIL, 1997).
Em 2004, o Ministério da Saúde e o Conselho Nacional de Combate à Discriminação lançaram o Programa 'Brasil sem Homofobia'. Este programa iniciou uma campanha de combate a homofobia e conseguiu reunir forças vindas de diversas outras áreas do conhecimento, articulando governo federal e sociedade civil organizada. O objetivo era/é de proporcionar mudanças nos vários setores sociais passando pelo legislativo, científico, educacional até atingir a população em geral. Parte do programa direcionado à educação distribui cartilhas e visa capacitar professores para o respeito da homossexualidade. Dentre outros itens, traz também esclarecimento de termos envolvidos nos artigos e discussões sobre a sexualidade e homossexualidade, como identidade sexual, orientação sexual, homossexualidade, gay, lésbica, transgêneros, transexuais e outros.

Tendo em vista vários estudos e dados que apontam à existência da homofobia dentro das escolas brasileiras e o decorrente comprometimento da formação e construção de identidade de crianças e jovens, do processo de aprendizagem, permanência e prosseguimento dos estudos, o interesse ao apresentar relatos de alunas e ex-alunas não é constatar simplesmente se os sujeitos envolvidos sofreram preconceitos, nem se os estereótipos interferiram na relação direta entre alunos, professores e gestores, mas sim compreender a experiência vivida diante da problemática da homossexualidade, compreender como se deu a constituição e o reconhecimento enquanto sujeitos com variadas formas de sexualidade na convivência com os outros nas escolas.

\section{Metodologia}

Os sentidos aqui reproduzidos foram obtidos junto a mulheres que se autodeclararam lésbicas ou vivenciando relações homoafetivas. Pretende-se, ora confrontando ora articulando, refletir sobre as teorias e as representações sociais sobre mulheres que fogem a definições presentes em livros e em discursos oficiais encontrados em muitas escolas brasileiras.

Entendendo que as relações sociais entre alunos, professores, gestores e demais funcionários são construídas histórico e culturalmente, as experiências de vida relatadas pelos sujeitos foram analisadas seguindo a perspectiva histórico-cultural e a teoria da dialogia de Bakhtin, para quem o papel da linguagem, das interações e mediações sociais e dos processos de significação é fundamental na compreensão dos fenômenos humanos. Teoricamente o trabalho também 
está apoiado nos estudos de Foucault sobre a relação que a linguagem tem com o poder. Aquilo que é dito e o modo como é dito define o lugar de cada um no meio social e não pode ser ignorado nem tratado de modo superficial.

Segundo Foucault, a identidade não é algo dado, mas está em permanente construção e realiza-se nos variados espaços públicos por onde os indivíduos circulam, negociam e renegociam com os outros. A escola por receber crianças e jovens em processo de formação de identidade deveria tratar a sexualidade com mais profundidade e não apenas como um 'apêndice'do currículo.

O termo 'sentido' segue o entendido por Vygotsky (1987, p. 276), ou seja, “o sentido de uma palavra é o agregado de todos os fatos psicológicos que emergem em nossa consciência como o resultado de uma palavra". Diferenciando-se de, mas ao mesmo tempo articulando-se a, 'significado' que, no dizer de Cruz (1995, p. 30): "são as formas linguísticas historicamente estabilizadas para um determinado grupo cultural", reconhecendo que essa estabilidade não é sinônima de estaticidade. Segundo Cruz (1995), ao analisar o que Vygotsky entendia por sentido e significação, uma palavra pode ter natureza dupla:

A palavra explicita, mas também apenas insinua, abreviando-se; ela é múltipla, fluida, mas conserva uma unicidade; ela é inconstante e mutável, sem deixar de apresentar uma certa estabilidade. É esta natureza que permite que, nos processos de produção de significação, a palavra articule sentidos relacionados às condições da interlocução e significados que permanecem estáveis no decorrer das alterações do sentido (CRUZ, 1995, p.30).

Com isso, podemos afirmar que a atividade mental do sujeito, assim como sua expressão exterior, constitui-se a partir do território social. É na interação verbal que a palavra se concretiza como signo ideológico, que se transforma e ganha diferentes significados, de acordo com o contexto em que ela surge. O diálogo constituído pela interação social se revela como forma de ligação entre a linguagem e a vida.

A relação entre sexualidade e representações sociais sobre os homossexuais passa pela escola e pelos sentidos produzidos por educadores e alunos. Os depoimentos apresentados não se propõem a denunciar a escola como sendo simplesmente discriminatória e heterossexista, um lugar de exclusão de muitos jovens e adolescentes, objetivam pensar na desconstrução de representações sexuais estigmatizadas e de processos de dominação. A escola deve ser um espaço de construção de um saber 'emancipatório' e de' autonomia', como diz Paulo Freire.

Os enunciados e depoimentos que apresentam os sentidos produzidos nas relações vividas na escola pertencem a alunas e ex-alunas que participam de grupos de discussão virtual sobre homossexualidade. Os grupos virtuais são: o DIADORIM, de Salvador (BA); o GAY-RIBS, de Ribeirão Preto (SP); o Grupo JAH, da cidade de São Paulo (SP); o M.O.L.E.C.A, de Campinas (SP). As doze mulheres tem entre 18 e 59 anos. Dentre elas, 03 possuem mestrado, 03 ensino superior, 05 cursam o ensino superior e 01 cursa o ensino médio. Em relação à moradia, uma mora sozinha, uma mora com o filho, 07 moram com os pais, uma mora com família juntamente com a companheira, uma mora com a companheira e uma mora com a companheira mais o filho. Diversas também são as profissões, sendo 05 são professoras, 01 estudante, 01 recepcionista, 01 naturóloga, 01 promoter/designer, 02 psicólogas e 01 bibliotecária.

A obtenção de dados por meio de por grupos de discussão virtual se deu por serem ambientes de que jovens e adultos se apropriam para comunicação, interação e, de certa forma, para permanecerem longe do controle familiar e social. Nos grupos virtuais os membros podem trocar confidências, experiências, podem expressar sentimentos, compartilhar desejos, dores, alegrias, fazer reivindicações, denúncias sem terem que se identificar. Seus membros acreditam que este é um espaço muito importante para os homossexuais e para as pessoas com variadas sexualidades, pois abre possibilidades de poderem se expressar livremente sobre suas experiências. É possível notar dentre os membros dos grupos a necessidade de pertencimento social, o desejo de sentir-se integrados, pertencentes a grupos que discutam temas que lhes digam respeito, interagindo com vários outros.

$\mathrm{Na}$ busca dos sentidos que são atribuídos por mulheres às relações sociais vividas na escola em referência à própria homossexualidade, há que se ter um cuidado especial à linguagem utilizada por elas, pois sabemos que a linguagem na sua forma mais ampla proporciona aos sujeitos a constituição/formação com o mundo, com os outros e que essa constituição não se dá de forma passiva, tranquila, mas em conflito, negociações. A concepção de linguagem adotada está centrada na linguagem em uso. Ou seja, a linguagem é entendida como prática social. As condições de produção da linguagem são entendidas aqui tanto como contexto social e de interação verbal no sentido bakhtiniano, quanto no

Patricia Magri Granúzzio 
sentido foucaultiano de construções históricas.

Analisar o discurso, a fala dos sujeitos, seguindo Bakhtin, é partir da compreensão de que linguagem e realidade não coincidem de forma absoluta. $O$ que se diz sobre a realidade e sobre as próprias vivências não remete de forma transparente ao vivido. Porque reflete e refrata o vivido, o discurso revela muitas vezes diferenças entre o que se fala e o que se vive, contradições em seus argumentos e justificativas sobre a experiência. Essa compreensão da realidade e da própria experiência é sempre elaborada em relações dialógicas, que constituem o discurso do próprio sujeito. E diálogo, em Bakhtin, envolve tensão e conflito. Por meio da análise do que se diz, como se diz e até onde se sustentam os discursos é que realmente é possível analisar de que forma as pessoas foram se constituindo e de que forma foram criando redes de proteção ao vivenciado, que valores foram atribuindo a essas vivências.

No caso dos grupos virtuais, quando diante de algumas questões para o coletivo, podemos notar a força do grupo, a argumentação, os protestos, as denúncias; porém, quando as questões são individualizadas, notamos uma mudança sutil: as fragilidades, os medos, as solidões, as dores ficam mais evidentes, o discurso cria uma nova característica, uma nova roupagem, menos agressiva. Isso é compreensível, visto que diante de questionamentos e reflexões pessoais, utilizam em maior profundidade a identidade subjetiva, recorrendo às suas memórias individuais para reconstruir o passado vivenciado; ao passo que, quando está no grupo, em uma discussão da qual fazem parte mais pessoas, cada sujeito recorre à sua identidade e à identidade coletiva que lhe dá suporte e força, o contexto do grupo que lhe serve de referência transforma o seu eu em um eu coletivo, conforme afirma Baptista (2002): "o eu se configura a partir das relações sociais que permitem a cada um observar papéis, assumi-los e obter a confirmação do seu exercício através de outros indivíduos significativos".

\section{Mulher Homossexual e os Sentidos Produzidos nas Relações dentro da Escola}

Embora um relativo avanço possa ser percebido nas orientações oficias e nos programas governamentais, em relação à educação sexual, vê-se que o tema da homossexualidade não tem sido objeto de orientações e/ou ações mais explícitas e efetivas. Além disso, se a sexualidade humana, em geral, é tema que tem enfrentado grande resistência nas escolas, quando envolve a homossexualidade, a resistência é ainda maior. E, nesse caso, não basta dizer que ela é resultado puro e simplesmente do desconhecimento e/ou despreparo de professores em relação ao tema, ou da 'ignorância' de alunos e da comunidade. A questão é cultural, enraizada em aspectos diversos, inclusive religiosos (HELMINIAK, 1998). Não é simplesmente uma questão de esclarecer, informar ou ensinar, mas sim de desconstruir verdades tidas como absolutas sobre o sexo, que interferem na constituição das identidades e discutir sobre os novos caminhos abertos para aquilo que não é novo, mas é pouco discutido dentro da formação docente. É, como diz Foucault (1988), questionar o sagrado, o estabelecido pela sociedade como algo natural.

A intolerância à homossexualidade, ou seja, a homofobia, atinge dimensões chocantes e requintes de crueldade em nosso país, fruto de uma ideologia machista e heterossexista. Para muitos, a homossexualidade ainda é uma anomalia, um desvio de conduta a ser tratada com psicólogos ou psiquiatras, uma doença que pode ser curada (MASTERS E JOHNSON, 1979).

Há tempos os homossexuais vêm sofrendo preconceito e discriminação em nosso país. Muitas das crianças, adolescentes, jovens e adultos pertencentes a outras minorias como as raciais, étnicas, religiosas, encontram apoio na família, têm em casa o estímulo para a autoestima que não encontram ou não recebem na sociedade, criando possibilidades para enfrentar o preconceito, isso já não acontece com a maioria dos gays, lésbicas, bissexuais, travestis e transexuais. Em muitos casos, a família é a primeira a discriminar, agredir fisicamente ou moralmente com insultos, humilhações, o que resulta, muitas vezes, em expulsão do lar ou até mesmo em suicídio. Quando uma família suspeita que uma filha revela tendências homossexuais, todos os recursos são acionados a fim de corrigir e curar a indesejada 'anormalidade'. Broncas, surras, castigo, humilhações, tratamentos médicos, internações - vale tudo na luta para não se manchar a honra da família. Até mutilações fazem parte desta sinistra 'cura' (ORAISON, 1997). Eis o depoimento de uma professora de educação física de São Paulo, que consta de um livro de Luiz Mott (1987):

No ano passado meus pais fizeram tudo para eu assinar uma autorização em que concordava ser operada da cabeça. Lobotomia. Trata-se da remoção total, pura e simplesmente, de uma partezinha do cérebro responsável pela capacidade que a gente tem de sentir as coisas eroticamente.

Patricia Magri Granúzzio 
Quer dizer, se eles me operam, eu paro mesmo de sentir atração por qualquer coisa! Para os meus pais, para os psiquiatras, para um monte de gente, o que eu sinto é uma coisa horrenda, nojenta. Quase ninguém, quando fala das lésbicas, fala em amor. E é amor que eu sinto pela Zumba, minha namorada (MOTT,1987, p. 84).

Do mesmo modo que acontece em boa parte das famílias e na sociedade em geral, quando a questão é a homossexualidade, a escola se cala ou perpetua a discriminação. De acordo com Mott, os professores e professoras, seja em escolas primárias, seja nas universidades, não podem dizer publicamente que são homossexuais, sem perder seus empregos. Isso se dá porque nossa sociedade é heterossexista e homofóbica; teme que seus mestres digam a verdade científica em suas salas de aula, temem que os alunos aprendam "que todas as expressões sexuais, desde que respeitem a liberdade alheia, são igualmente válidas, legítimas e saudáveis" (MOTT, 1985, p.117).

Como todo ser social, o jovem tem uma necessidade de pertencimento, de ser aceito, amado, porém, lida muito mal com as recusas, exclusões ou inclusões inadequadas. A sociedade criou e até hoje é alimentada por regras sociais que ora incluem ora excluem as pessoas; os que fogem ao estabelecido como padrão ou modelo de bons costumes como, por exemplo, o modelo heterossexual, a beleza europeia, a religião católica, são muitas vezes excluídos. Segundo Britzman, os homossexuais passam por uma aprendizagem diferente:

uma diferente forma de aprendizagem para o ocultamento é muito mais insidiosa. Ela diz respeito a uma dupla negação: dos significados das práticas sexuais da pessoa e da dor de se ter o corpo disciplinado. Enquanto os jovens gays e as jovens lésbicas estão atarefadamente construindo suas identidades, eles/elas sempre encontram representações contraditórias e hostis de seu trabalho de identidade. (...) Ocultar a sua homossexualidade quando já se pressupõe que ela não existe pode ser a resposta mais razoável à hostilidade estatal e à hostilidade generalizada contra as homossexualidades (BRITZMAN, 1996, p. 82-83).

Entretanto, não é só silenciamento e repressão que marcam as práticas escolares, em relação à sexualidade e à homossexualidade. Cortez e Souza (1997, p.14), baseadas em Foucault, observam que a escola passou a falar regularmente de sexo, não preocupada com o prazer, mas sim com sua regularização, passando a vigiar constantemente a criança, confinando cada vez mais a infância nas escolas, separando meninos de meninas e combatendo sem trégua a masturbação. Pela escola passam todas as ideias que uma sociedade quer transmitir a seus cidadãos para conservar tudo aquilo em que eles acreditam ou que uma boa parcela quer que se acredite. Um bom exemplo de que nossa forma de pensar está diretamente condicionada pela sociedade a que pertencemos, tanto pela cultura quanto por sua história, é o fato de que muitos ainda acreditam que a homossexualidade é um defeito apresentado por algum cromossomo ou ainda que pais problemáticos induziriam, involuntariamente, alguém em sua orientação sexual. Por mais absurda que possa ser uma ideia, sendo bem manipulada e comprovada 'cientificamente', ela pode se perpetuar durante décadas e, assim, tornar-se parte constitutiva do sujeito.

Um dos conceitos de Bakhtin importante para a discussão da homossexualidade é a importância do outro na formação subjetiva do ser humano. Bakhtin pensa o sujeito sempre na relação com a alteridade. Desse modo, o eu só existe quando em interação com o outro, porque "ser significa ser para o outro e, através dele, para si mesmo" (BAKHTIN, 1984, apud. BEZERRA, 1998). Assim como o sentido de um enunciado é construído na interação verbal, por meio do contato com outros sentidos dados por outros interlocutores, a subjetividade se dá apenas na relação do eu com o outro. Segundo Lodi (2006, p.03):

o eu bakhtiniano não se constitui isoladamente, não é algo acabado e completo; existe apenas em uma relação tensa e dinâmica com aquilo que é outro (...). Meu eu só é percebido pelos olhos do outro, na refração do mundo através dos valores do(s) outro(s).

No entanto, a relação 'eu/outro', na qual minha autoconsciência é constituída, não é simples. Para Bakhtin (1970-1971/1979), esta relação, dialógica em essência, é fundada numa tríplice distinção: o 'eu-paramim' (representação que o eu faz sobre si próprio), o 'eu-para-o-outro' (representação do eu devolvida pelo outro) e o 'outro-paramim' (representação que o eu constrói do outro) (LODI, 2006, p.03).

Desse modo, visando compreender 'que sentidos são atribuídos por alunas e ex-alunas às relações 
sociais vividas na escola em referência à própria homossexualidade', procurou-se nos enunciados das participantes da pesquisa sua dimensão axiológica, visto que "não há enunciado neutro. Todo enunciado emerge sempre e necessariamente num contexto cultural saturado de significados e valores e é sempre um ato responsivo, isto é, uma tomada de posição neste contexto" (FARACO, 2006, p. 26).

A análise dos enunciados não está centrada somente nos aspectos explicitados, mas também nos indícios que se fazem presentes. As leituras dos dados, aliada à interlocução entre a bibliografia sobre o tema da homossexualidade e o referencial teórico adotado para a análise dos dados, possibilitaram a construção de eixos temáticos. Esses eixos temáticos que focaram as relações sociais, as questões de identificação, discriminações e preconceitos, sempre em uma perspectiva bakhtiana, foram agrupados da seguinte forma: I. O que é dito e o que é silenciado; II. Ver-se (ou não ver-se) no outro: possibilidades de identificações; III. Entre a visibilidade e a invisibilidade.

\section{I- 0 que é Dito e o que é Silenciado}

Segundo Miskolci (2005a), as escolas tendem a tornar invisível a sexualidade em um jogo de pressupostos, inferências não apresentadas e silêncios. De acordo com ele, pressupõe-se que a sexualidade é assunto individual ou restrito ao lado de fora da escola; entretanto a sexualidade está presente porque faz parte dos sujeitos o tempo todo e não há maneiras de alocála no espaço ou em algum período de tempo. Para ele, ninguém se despe de sua sexualidade ao adentrar em algum lugar como um acessório do qual pode se despojar. A 'neutralidade' em relação à sexualidade nada mais é do que um silêncio diante do incomodo causado por um estudante que age de modo distinto da maioria. Seria sim uma tentativa de eliminá-lo fingindo que ele não existe, ignorar a diversidade sexual costuma ser uma boa forma de fazer valer os padrões de comportamento considerados adequados, bons, corretos e normais. Miskolci alerta que esse silêncio é uma tentativa de ignorar o diferente e denota cumplicidade com os valores e padrões de comportamento hegemônicos.

Sobre o envolvimento de professores e gestores na discussão da sexualidade humana, é comum a afirmação, entre as participantes, de que a escola, principalmente nos níveis do ensino fundamental e médio, mantém o silêncio diante dessa questão:

É muito raro que algum deles se envolva nesse tipo de questão. Nunca, durante a minha vida escolar, um professor deu alguma informação esclarecedora sobre homossexualidade ou bissexualidade, ou sequer intercedeu na defesa de alguém injustiçado numa discussão com essa temática. Mas acredito que seja mais por falta de informação que por falta de vontade. $O$ setor educacional, como um todo, é despreparado nesse aspecto (And, 18).

Por onde estudei o posicionamento dessas pessoas frente a uma situação desse tipo era geralmente de ausência ou falta de posicionamento claro. $O$ que, no meu entendimento, contribui para a permanência do preconceito (Ana, 27).

Os sentidos atribuídos tanto ao silêncio diante da diversidade sexual quanto à educação normativa tem relações com respeito, o enunciador ressignifica esse silêncio dando a ele valor positivo; as relações que não envolvem violência são vistas como boas, normais, elas se sentem pertencendo ao grupo de colegas. $\mathrm{O}$ desejo de pertencimento vem do querer estar integrado e em segurança. Se pensarmos o que é estar integrado e seguro, podemos encontrar variados sentidos, significados e contradições.

Toda identidade de gênero é produzida histórica e socialmente. A aparente naturalidade foi desconstruída teoricamente, mas ainda hoje, é um forte mito social, que contribui para a manutenção das desigualdades sociais, através da valorização de padrões considerados superiores. Em relação às identidades homossexuais, ocorrem também valorizações sociais e consequentes naturalizações. Miskolci (2005b) comenta que os termos gays e lésbicas são utilizados para nomear e autonomear pessoas homossexuais de classe média, predominantemente brancos, com nível universitário e tendentes ao agnosticismo; para aqueles que não se enquadram nesse padrão, termos mais vulgares seriam utilizados:

Na escola de enfermagem, quando passei disseram: olha lá, vem vindo o sapatão, eu parei, olhei bem pra elas e perguntei se estava tudo bem, elas ficaram constrangidas e nunca mais nem sequer olharam pra mim novamente, mas acho que era despeito mesmo (Clad, 25).

As identidades gays e lésbicas, assim como toda e qualquer identidade, são socialmente construídas e estão em constante transformação. Louro (2004), 
analisando os movimentos dos homossexuais e os objetivos que envolvem as identidades sexuais, afirma que estas não são fixas, desafiam as fronteiras dicotômicas, as dualidades:

Em termos globais, multiplicam-se os movimentos e os seus propósitos: alguns grupos homossexuais permanecem lutando por reconhecimento e por legitimação, buscando sua inclusão, em termos igualitários, ao conjunto da sociedade; outros estão preocupados em desafiar as fronteiras tradicionais de gênero e sexuais, pondo em xeque as dicotomias masculino/feminino, homem/mulher, heterossexual/homossexual; e ainda outros não se contentam em atravessar as divisões, mas decidem viver a ambiguidade da própria fronteira. A nova dinâmica dos movimentos sexuais e de gênero provoca mudanças nas teorias e, ao mesmo tempo, é alimentada por elas (LOURO, 2004, p. 37).

Dentre as participantes dos grupos virtuais de discussão, encontramos pessoas que desafiam e rompem com os padrões e fronteiras estabelecidos, mas também encontramos aqueles que negam as discriminações e preconceitos vividos.

Apenas uma vez fui agredida indiretamente por uma colega de classe que perguntou 'este banheiro é de homem?', mas logo disse a ela 'não, é de mulher' e falei que ela estava sendo preconceituosa e isso poderia levá-la a responder juridicamente se continuasse. Nunca mais ela me dirigiu a palavra (Zorayona, 33).

Já escutei comentários, mas isso eu acho normal. Fico triste, mas sei que é normal as pessoas comentarem, assim não considero preconceito (Patrícia, 21).

Segundo Bauman (2005, p.28), “o 'pertencimento' teria perdido o seu brilho e o seu poder de sedução, junto com sua função integradora/disciplinadora, se não fosse constantemente seletivo nem alimentado e revigorado pela ameaça e prática da exclusão". A escola é uma das instituições que costuma apresentar claramente as distinções de gênero, trabalhando diferentemente com meninos e meninas, ela não é a única a estabelecer estratégias de controle e incentivo aos papéis sexuais, mas, pelos anos que crianças e jovens a frequentam, seu papel tem sido importante.
Sobre esse controle exercido, Louro (2000, p.41) comenta que a escola continua empenhada em 'ensinar' os papéis masculinos e femininos visando a garantir que seus meninos e meninas se tornem homens e mulheres 'verdadeiros', ou seja, homens e mulheres que correspondam às formas hegemônicas de masculinidade e feminilidade tidas como padrões aceitáveis. Entretanto, esse controle sobre a sexualidade das crianças e jovens nem sempre é explícito, um olhar crítico sobre o cotidiano escolar tem revelado práticas reformadas e mais sutis de discriminação sendo exercidas. Nessa mesma direção, a linguagem ensinada faz parte desse controle, havendo inclusive um vocabulário inadequado para as alunas, mas, de certo modo, aceitável quando dito por alunos, ocorrendo o que Britzman (1996, p.78) chama de oferecimento de representações de versões socialmente normalizadas do adulto e da criança, da mulher e do homem.

Pelos enunciados apresentados pelas participantes vemos que no senso comum e em muitas escolas ainda circulam os discursos que alguns movimentos GLBT e os acadêmicos que pesquisam sobre a temática acreditam já terem sido superados, alguns depoimentos vêm reiterar que muito do que já foi pesquisado, discutido e tido como superado em relação às diversas sexualidades ainda não chegou às escolas e a algumas universidades. Muitos homossexuais continuam a ser vistos e tratados como doentes, como 'anormais' e têm seus direitos mais básicos negados:

Deveria ser colocado esse tema em disciplinas que são indicadas a trabalhar com isso, como a educação física e ciências. Considero muito importante a informação, pois é muito difícil à aceitação própria, foi muito difícil conviver com uma culpa e com medo da sociedade parecendo que estava com uma doença ruim (Patrícia, 21).

Para as participantes da pesquisa, as informações e conhecimentos transmitidos pela escola sobre a sexualidade fizeram parte de um discurso classificado por Bakhtin como monofônico, isto é, um discurso autoritário em que diversas vozes foram silenciadas, abafadas. Os diálogos ficam ocultos e os conteúdos colocam-se como verdades absolutas e inquestionáveis:

A prevenção de doenças e de gravidez era a temática principal. Neste ponto, acho que as palestras e informações são bastante proveitosas. Mas o assunto sexualidade humana não passava de relações 
heterossexuais e era geralmente bastante limitado à penetração vaginal. Por fim, acabava por fazer as pessoas pensarem que o normal era aquilo, já que só se falou daquilo. Se desde o princípio destes trabalhos se abordassem todas as formas da sexualidade humana, acredito que contribuiria muito para destruir alguns preconceitos (...). Desde cedo se ensinam crianças apenas o modelo cristão de família (papai, mamãe e filhinhos). Quando se fala de sexualidade humana, limita-se à reprodução (o que na prática, sabemos, é busca de prazer) e por conta disso, limita-se à relação heterossexual. Isso faz com que as pessoas pensem que aquilo é o 'normal' $e$ que qualquer coisa que fuja daquilo seja anormal (And, 18).

A mesma baboseira que chega até cair no vestibular: HIV, DST, gravidez, modificações comportamentais e hormônios (Tee, 21).

Foram abordados temas como, menstruação, puberdade, sexo entre menino e menina, mas nada de específico sobre homossexuais (Clad, 25).

Os sentidos atribuídos pelas participantes homossexuais a esses discursos deixam claro que nas informações recebidas, nos fatos e dados apresentados e nas relações vividas não houve diálogos e polêmicas não foram levantadas, não houve cruzamento de vozes, de interpretações e questionamentos sobre a construção histórico-cultural da sexualidade tida como natural e normal.

[Que significados o trabalho desenvolvido pela escola teve] Poucos. A maioria das informações eu já tinha, por curiosidade minha, por internet, livros ou mesmo na família. Mas acho importante por que para muitos isso não é tão claro (And, 18).

Nenhum. Apesar de formalmente eu já ter tido uma disciplina quinzenal chamada 'Orientação Sexual' eu tinha mais condições de ensinar minha professora do que aprender com ela (Tee, 21).

Nesses discursos, a significação é somente baseada no/na professor/a e nos conteúdos propriamente ditos, ignorando o/a estudante e os sentidos que eles/as atribuem a partir de suas experiências, desejos e anseios. Discursos ligados à questão de poder e dominação. Sobre os discursos Foucault afirma que:

(...) Os discursos, como os silêncios, nem são submetidos de uma vez por todas ao poder, nem opostos a ele. É preciso admitir um jogo complexo e instável em que o discurso pode ser, ao mesmo tempo, instrumento e efeito de poder, e também obstáculo, escora, ponto de resistência e ponto de partida de uma estratégia oposta. $\mathrm{O}$ discurso veicula e produz poder; reforça-o mas também o mina, expõe, debilita e permite barrá-lo. $\mathrm{Da}$ mesma forma, o silêncio e o segredo dão guarida ao poder, fixam suas interdições; mas, também, afrouxam seus laços e dão margem a tolerâncias mais ou menos obscuras (FOUCAULT, 1988, p. 95-96).

Os enunciados dos sujeitos participantes estão marcados por tensões, por jogos apontados por Foucault em relação à sexualidade. Quando o tema sexualidade era trabalhado nas escolas, alguns conseguiram romper com o que estava programado, conseguiram abrir caminhos para novas discussões, possibilitando a constituição de discursos de reação, os sujeitos homossexuais puseram-se a falar de si mesmos e por si mesmos, a reivindicar um espaço:

Tenho professores que tem um posicionamento mais retrogrado, mas são muito poucos, e nem abordam esse tema mais em sala de aula, às vezes fazem alguns comentários, como 'coisa de viado'... etc., mas recebem tantas criticas que não abordam isso abertamente. Nas aulas de psicologia, política social, etc., já debatemos temas sobre sexualidade, inclusive a questão GLBTT, pois eu insisti que deveria ser discutido... (Telma, 20).

Os discursos de reação não surgiram apenas nas aulas, quando o tema era algo relacionado à sexualidade, surgiram nos momentos de tensão, nas brigas, nos enfrentamentos, e os sentidos atribuídos a esses discursos foram ora de reconhecimento e vitória ora de diálogos naturais. O silêncio em relação à sexualidade começa gradativamente a ser rompido nos níveis superiores da educação brasileira, na produção de conhecimentos sobre a homossexualidade não estão apenas participando os militantes de grupos organizados, os acadêmicos e pesquisadores da temática, mas também os sujeitos que frequentam as 
escolas brasileiras como estudantes que refletem sobre a construção social dos significados associados à homossexualidade, construção de conhecimentos enquanto atitude política. Essa construção tem sido notada também entre os professores que fizeram parte desta pesquisa, bem como os momentos sofridos de discriminação, humilhações e rejeições:

Como mestranda, trabalhamos com
questões de gênero e sexualidades, e há
sempre muitos depoimentos, troca de
experiências entre mulheres, é muito
interessante $(B a u, 49)$

Pelos enunciados apresentados pelos participantes vemos que no senso comum e em muitas escolas ainda circulam os discursos que alguns movimentos GLBT e os acadêmicos que pesquisam sobre a temática acreditam já terem sido superados, alguns depoimentos vêm reiterar que muito do que já foi pesquisado, discutido e tido como superado em relação às diversas sexualidades ainda não chegou às escolas e a algumas universidades. Muitos homossexuais continuam a ser vistos e tratados como doentes, como 'anormais' e têm seus direitos mais básicos negados:

Não só pode, deve [ser trabalhado o preconceito contra homossexuais em sala de aula]. É extremamente necessário que se explique que homossexualidade não é um defeito genético, não é uma doença, não é uma mutação entre outros absurdos. Muitas crianças e adolescentes chegam à sala de aula com conceitos formados sobre isso. Conceitos errados, que geralmente aprenderam em casa, na igreja ou pela televisão. A escola, ao ignorar este fato, se torna uma destruidora de autoestimas juvenis e não uma formadora de cidadãos (And, 18).

Deveria ser colocado esse tema em disciplinas que são indicadas a trabalhar com isso, como a educação física e ciências. Considero muito importante a informação, pois é muito difícil à aceitação própria, foi muito difícil conviver com uma culpa e com medo da sociedade parecendo que estava com uma doença ruim (Patrícia, 21).

O que vemos hoje é uma valorização da diferença, que, na maioria das vezes, disfarça-se em indiferença, ocultando o que é desigual. Na realidade, o sentido e o significado da diferença têm sido esvaziados de sua força e está tornando-se fala comum (ABRAMOWICZ \& SILVÉRIO, 2005). É necessário refletir que aceitar um discurso diverso não pode impedir que sejam analisadas as relações envolvidas como as forças desiguais que o produz. Os discursos não podem ser analisados sem conflitos e tensões, pois os lugares de onde são produzidos não são necessariamente lineares e harmoniosos e, na grande maioria das vezes, escondem suas intenções e poderes de dominação.

A escola e a educação que ela transmite é vista com esperança por alguns, entretanto, nos enunciados das professoras vemos que não há diferenças marcantes. Elas, enquanto estudantes enfrentaram discriminações e preconceitos por parte dos colegas estudantes; hoje são discriminados ora por colegas de trabalho ora pelos próprios alunos:

Fundamental [o preconceito contra homossexuais pode ser trabalhado em sala de aula]. A tolerância raramente vem de casa. Pelo contrário, os pais tendem a cobrar uma heterossexualidade de seus filhos. O único contrapeso nessa balança seria a escola (Tee, 21).

Com a maioria das colegas a relação é de impessoalidade e objetividade voltada para os assuntos acadêmicos, dentro do grupo de colegas acadêmicos tenho alguns poucos amigos que tem uma relação mais próxima de minha vida pessoal e emocional (Jocarego, 30).

Eu responderia hoje, como professor, 'em termos'. Nunca sofri uma discriminação explícita. Minha orientação sexual não é escondida mas também não é proclamada. Acredito que haja manifestações sutis por parte de colegas e alunos (Elídi, 31).

Os enunciados apresentados pelos sujeitos demonstram que, apesar de todas as dificuldades e silenciamento encontrado pelos que cruzam as fronteiras da sexualidade normativa ou que nelas vivem, muitos deles desejam que a questão da homossexualidade seja trabalhada/discutida nas escolas, acreditando assim que será possível uma mudança em relação à discriminação e preconceitos. Criticam as relações sociais que acontecem na escola, apontando que, se por um lado não há mais exclusões explícitas, casos de transferências e expulsões da escola, por outro lado casos sutis de preconceitos e discriminações continuam a interferir negativamente 
na educação, na autoestima dos alunos e na construção de sua identidade. Enquanto professores, os sujeitos homossexuais estão empenhados duplamente na produção da sexualidade, em seus corpos e no discurso diante de outros docentes e diante de seus alunos. Esse processo, por sua vez, assim como os demais processos de constituição, não é realizado conforme eles desejam e isentos de tensão ou constrangimentos. Participantes ativos da construção histórico-cultural da homossexualidade, eles ao mesmo tempo em que se defrontam com padrões heterossexuais a serem seguidos no exercício da docência, veem-se diante das possibilidades de transgressões e mudanças nesses padrões. Mas, como salienta Louro (2001, p. 31), a afirmação das identidades historicamente subjugadas em nossa sociedade vai se tornando visível e perceptível, mas essa visibilidade não ocorre sem dificuldades, assim, "assumir a condição de homossexual ou de bissexual é um ato político e, nas atuais condições, um ato que ainda pode cobrar o alto preço da estigmatização":

Me sinto injustiçada, revoltada, às vezes excluída, até mesmo os meus alunos são excluídos das atividades da escola (Bea, 41).

\section{II - Ver-se (ou Não Ver-se) no Outro}

As falas sobre as relações entre eles, professores e equipe de gestores revelam enunciados em que há sujeitos que se veem nos outros e há sujeitos que não se veem nos outros. Isso é natural, afinal nem sempre uma pessoa se vê na outra o tempo todo, o que acontece é que muitas vezes, no caso da homossexualidade, as possibilidades de identificação com o outro são negadas àqueles que não se enquadram nos padrões da heterossexualidade. Questionados sobre as relações com colegas de escola, alguns sujeitos afirmaram ter sido 'boas', 'excelentes', 'normal', esses se viram, ou pensaram ter se visto, nos outros, a voz do outro-outro sendo constitutiva desse eu:

Era boa, mas não tinha nenhum contato fora da sala (Bea, 41).

Como as relações não se estendiam para além dos espaços reservados para os processos educativos escolarizados, a fala de Bea permite entrever que, para ela, sustentar boas relações escolares implicava não estreitá-las, não as tornando íntimas. Questionados sobre as relações com colegas de escola, alguns sujeitos não se viram no outro e ainda afirmaram que havia receio de críticas. A construção da subjetividade se dá na relação do eu com o outro e, comumente, apresenta tensões, quando envolve a sexualidade, há ainda mais categoriais e representações de identidades que são oferecidas e policiadas. Britzman (1996, p. 75) afirma que as dinâmicas ou momentos de identidade que dizem respeito aos contextos e condições sociais da formação de identidade para a juventude gay e lésbica na educação são, geralmente, sombrias, hostis e repressivas e se questiona que realidades e discursos contraditórios estão em ação quando essas identidades são 'saudadas' pelo conhecimento escolar, pela pedagogia e pelos/as professores/as. Uma exceção pode ser vista no enunciado de uma professora:

Tive uma professora que acho deveria ser lésbica, pelo estilão dela, e às vezes as pessoas comentavam sobre ela, e ela nem se abalava, a tranquilidade e segurança dela me ensinavam a não me importar com comentários alheios (Clad, 25).

Não se ver no outro interfere na constituição da subjetividade, segundo alguns participantes eles não apenas não se viam nos colegas, professores e gestores como também não se viam nos materiais utilizados nas escolas, dentre eles o livro didático. O tema da homossexualidade além de estar nos livros didáticos, segundo os sujeitos da pesquisa, deveria permear todo o currículo das escolas. Contribuiria para uma convivência mais harmoniosa e menos sofrida, a importância não se limitaria aos homossexuais, ensinaria a todos o respeito pelas diferenças:

Eu teria me aceito mais cedo e com mais facilidade, tive problemas comigo mesma da minha própria aceitação (Kika, 29).

Eu me sentiria menos só, poderia me ver (Bau, 49).

Nas décadas passadas as figuras femininas que apareciam nos livros didáticos, deixavam sinais de uma sociedade machista, na qual a submissão feminina era reforçada e tida como ideal social. Outros grupos eram igualmente discriminados como os negros e os índios, esses apareciam apenas como figuras ilustrativas que reafirmavam as diferenças e desigualdades sociais, apresentando estereótipos de incapacidade, desmerecimento e inferioridade. Há poucos anos podemos observar uma gradual mudança e algumas publicações recentes parecem abordar estas questões e grupos de forma diferenciada, mas ainda não contemplou os homossexuais. As pesquisas e

Patricia Magri Granúzzio 
denúncias em relação ao silêncio das edições de livros didáticos sobre questões da homossexualidade se fazem de extrema importância para que as pessoas possam, por meio da escola, ter conhecimento e contato com realidades mais amplas além das suas próprias.

Para os participantes, o contato com livros, textos, notícias de jornais que falem a respeito de homossexualidade de modo sério é fundamental para uma abertura das mentalidades e maneiras de viver e ver as sexualidades:

Tornaria menos 'assustadora' a notícia para meus amigos de que sou homossexual. Foi quase como dizer que eu era um E.T., algo que você nunca pensa que vai existir ou conhecer pessoalmente (Tee, 21).

O não ver-se no outro além de discriminações explícitas também envolvem relações classificadas como formais, distanciamentos, tensões; os sentidos elaborados pelos sujeitos quando falam das relações com os professores envolvem considerações irônicas, de desqualificação. Quando Ana, 27 anos, psicóloga, afirma em relação a contatos com diretores e/ou vicediretores "Nunca precisei chegar muito perto dessas figuras, o que entendo como positivo", revela múltiplos sentidos, podemos inferir que, enquanto aluna, ela teve um comportamento sempre adequado e os professores não precisaram encaminhá-la para esses profissionais ou ainda que, além disso, a visão que ela tem do papel costumeiro de diretores(as) e vice-diretores(as) é o da fiscalização, do controle, da punição. Manter-se longe deles(as) seria manter-se afastada do controle ou ainda não dar motivos para reprimendas ou punições. Assim como Ana, outros também não se relacionaram muito bem com os gestores.

Para as participantes, a própria aceitação é muito complicada enquanto adolescentes que se descobrem homossexuais, admitir que se é diferente, que se vivencia e deseja uma sexualidade diversa da que estabeleceram como padrão e normal significa para eles correr riscos, possibilidades de ser discriminada, apontada, marginalizada, excluída.

$\mathrm{Na}$ universidade minha relação com meus colegas e minhas colegas é como a de qualquer outra pessoa... eu respeito à orientação sexual deles e eles respeitam a minha. A maioria dos meus amigos são heteros. É claro que aqui existem pessoas preconceituosas, mas ao menos perto de mim ou de algum amigo meu não dizem nada sobre o assunto. No colegial foi mais difícil, porque eu não tinha assumido minha orientação nem pra mim mesmo. Eu fazia parte do 'grupinho do fundão' e quando vários adolescentes se reúnem, falar sobre a sexualidade alheia é a coisa mais divertida a se fazer (Telma, 20).

O processo de produção de sentidos nas práticas discursivas do cotidiano se insere no jogo das relações pessoais e este está em constante processo de negociação, ocorrendo trocas simbólicas, em um espaço de intersubjetividade ou interpessoalidade. Ao focalizarmos as práticas discursivas deparamos também com a processualidade das construções identitárias. Posicionar-se implica navegar pelas variadas narrativas com que entramos em contato e que se articulam nas práticas discursivas (SPINK e MEDRADO, 2000, p. 56). Desse modo, o reconhecerse é sempre um posicionamento relacionado às posições disponíveis nas práticas discursivas tanto dos que convivem com a pessoa quanto de qualquer outra pessoa que se expresse sobre a homossexualidade. Essas práticas narram histórias pelas quais se produzem sentidos em nossas vidas, os processos de socialização que possibilitam a construção de uma identidade que vá ou não ao encontro de determinadas expectativas, que pode envolver emoções variadas, tanto angústias, alegrias, dores, insegurança, etc.

\section{III - Entre a Visibilidade e a Invisibilidade}

Alguns enunciados apresentam fortes indícios em relação aos graus de sofrimento/dor/perseguição sofridos desde o ensino fundamental até o ensino superior. $\mathrm{O}$ modo como os alunos homossexuais eram vistos (ou não vistos), as discriminações e preconceitos foram se modificando e adquiriram formas mais sutis. Para alguns, as rejeições foram gradativamente diminuindo a cada nível escolar.

Quando crianças e na adolescência, percebemos que a discriminação é feita de forma declarada, as pessoas não cuidam tanto das palavras e gestos para se referirem aos outros, mas à medida que vão se tornando jovens e adultos, e, portanto, cada vez mais socializados e controlados, as formas de sinalizar o preconceito e a discriminação também vão sendo modificadas. Ao mesmo tempo em que se dá essa transformação nas maneiras em que alguém é excluído socialmente, também pode ocorrer uma aprendizagem: os indivíduos vão aprendendo a conviver com a fala do outro, com o olhar ou até mesmo com o silêncio do outro e, por meio desse aprendizado, constituindo-se e construindo mecanismos e canais de proteção, autodefesa que passam também a enfraquecer o outro.

Em muitas das falas dos participantes, o olhar que 
receberam em suas relações sociais na escola aparece como um olhar de crítica, desaprovação e pesar:

[Como eram as relações com diretores $e$ vices] Fui coagida, me senti sozinha, pressionada, sem poder expressar meus sentimentos (Bea, 41).

Se lembrarmos das falas de Telma sobre o fato de que na universidade em que estuda há pessoas preconceituosas, mas que perto dele nada dizem a respeito e que antes, no ensino médio era alvo de 'brincadeirinhas', objeto das 'gracinhas' do seu próprio grupo de amigos - do fundão - quando ainda não tinha assumido para si mesmo sua orientação sexual, ou seja, antes mesmo que pudesse se ver como homossexual veremos, mais uma vez, que a homossexualidade aparece relacionada à discriminação.

O desejo de ser visto pelo outro é a busca pelo reconhecimento do que sou, é o desejo da cumplicidade, da convivência, da troca, é ter por meio do outro a aprovação do que sou, ou ao menos a não indiferença. Quando o outro não me vê, ele não apenas está reprovando o que sou ou a minha imagem, mas muito mais do que isso: para ele deixei de existir, de ser algo bom ou ruim. O que resta é a indiferença, não somos indiferentes ao que vemos, mas sim ao que não vemos, o não ver possibilita a indiferença, o não desejo de interagir, conflitar, discordar, se as relações se dão através do outro-eu com o outro-outro, com a invisibilidade este outro deixa de existir.

Estamos passando por inúmeras mudanças sociais, é claro que com várias restrições e limitações, mas notamos uma pressão pelo respeito aos 'diferentes' que obviamente enfrenta forças tradicionais contrárias. Por meio das falas dos sujeitos participantes podemos notar que a pressão de organizações diversas para que haja mais respeito com os homossexuais tornou a discriminação e o preconceito mais sutis, mais velados. As falas revelam que isso é sentido como algo positivo, mesmo que de formas diferentes. Para eles, o silenciamento, aceitação parcial e a exclusão branda a que são ainda submetidos parece ser melhor que a violência explícita.

O confronto de vozes dos que defendem os direitos dos homossexuais e dos que os combatem radicalmente pode ser visto cotidianamente, de um lado organizações homossexuais lutando por mais direitos civis, religiosos, políticos e sexuais, de outro lado, pessoas e instituições que apresentam discursos conservadores em relação à 'moral e aos bons costumes'. Para estes últimos o perigo da 'desordem social' é representada, dentre outras, pela homossexualidade.

As transformações que vêm ocorrendo na sociedade brasileira têm suscitado questionamentos sobre as formas sociais de relacionamentos amorosos, sexuais, familiares, deixando o modelo social e tradicional de família em uma situação muito delicada. O que vem despertando em certos grupos o renascimento do discurso da preservação da família e seus valores tradicionais, vem provocando o que chamam de pânico moral. Hoje vivemos os pânicos morais diante das transformações percebidas nas relações de poder entre as identidades hegemônicas e aquelas que eram vistas como anormais e que em partes começam a ter algum tipo de reconhecimento. A fala de And remete ao chamado 'pânico moral', à ameaça que os homossexuais representariam para a ordem social.

Os sentidos que são atribuídos por sujeitos participantes da pesquisa a essa noção de moral e a esses pânicos morais é de impedimento de uma vida liberta das amarras sociais. Segundo eles, um certo medo moral reina nas relações sociais, no mercado de trabalho. Algumas escolas temeriam contratar profissionais homossexuais e teriam uma reação negativa por parte dos alunos e de suas famílias:

Fui dispensada de meu trabalho como professora em uma escola sem alegação evidente, mas todos os indícios foram de homofobia por parte da direção da escola (Bau, 49)

A maioria, de minha convivência são professores preconceituosos e hipócritas, mesmo os homossexuais, assumidos nos guetos que frequentamos, aqui no RJ, são homofóbicos (homofobia internalizada). Mais por medo do que tudo. Medo físico, medo de perder o emprego, medo da discriminação. $O R J$ hetero é muito retrógrado quanto a aceitar o homossexual na convivência aberta. Só os aceita nos guetos (Graça, 53).

Se para Bau, a homofobia é clara por parte da direção, para Graça a homofobia por parte de homossexuais não é apenas homofobia internalizada, mas resultado do pânico moral que reina em sua cidade. $\mathrm{O}$ contratante não seria necessariamente (ou apenas) uma pessoa homofóbica, mas teria receio de que ao contratar um homossexual fosse visto como alguém que contribui para que a ordem social seja perturbada.

Para os sujeitos participantes da pesquisa, de acordo com suas vivências, o olhar e papel do professor e dos gestores diante de atitudes preconceituosas em relação a homossexuais quando 
não tem sido de preconceito e omissão tem sido de opressão. Muitos não os veem, ou é como se olhassem através deles, como se fossem vidros transparentes:

Nulo. O assunto é tratado como tabu, melhor dizendo, sequer é tratado. Em toda minha vida escolar a 'homossexualidade' no máximo foi comentada três vezes e com não mais que cinco frases cada (Tee, 21).

O papel dos professores e dos gestores quase sempre é omisso, até mesmo pressionando os homossexuais a pedirem transferência (Bea, 41).

Por meio das falas de Tee e Bea vemos que essa invisibilidade ou omissão são percebidos por eles como uma maneira de não identificar a existência da homossexualidade dentro da escola e de não reconhecê-la como uma prática natural. Em relação à homossexualidade, para percebê-la o eu precisa olhar para o outro e tê-lo como real. É necessário que o eu olhe o outro, o perceba não como um estranho e nem reduzido ao que se mostra. Assim, para muitos professores, gestores e alunos, a homossexualidade não existe na escola e nem entre aqueles em que nela estudam ou trabalham simplesmente porque vê-la significaria percebê-la e percebê-la significaria admitir que há também possibilidades diversas de sexualidade e possibilidades de desconstrução das visões distorcidas da realidade. A omissão a que Bea se refere contradiz com a fala de que eles pressionam os alunos a pedirem transferência, omissão seria não mencionar, dizer ou escrever qualquer coisa que pudesse ser relacionada à homossexualidade, omissão seria não se posicionar

Uma atitude de não identificação inicial da homossexualidade em algum amigo ou colega pode significar, segundo as falas dos participantes, indícios de uma recusa da homofobia, considerada indigna e por isso, não autoadmitida; uma reação tida como natural, intrínseca à própria individualidade sobre o que não se discute ou reflete ou ainda mais uma intolerância às diferenças. Entretanto, a identificação não significa aceitação, a percepção pode resultar em afastamento; diante de discriminações devido à orientação sexual, os sujeitos afirmam terem se sentido desprezados e inferiorizados:

Mal, obviamente *rs. É um pouco frustrante que uma pessoa, de uma hora pra outra, mude todo o conceito que tinha sobre você por um detalhe tão irrelevante. Algumas vezes parece que quando você conta não ser heterossexual, tudo o que você já fez na vida anteriormente a isso deixa de ser importante, por que aquilo choca. Não deveria chocar. Deveria ser tão simples como dizer que seus pais são budistas ou que seu cabelo loiro na verdade é oxigenado (And, 18).

Para muitos dos sujeitos participantes, a escola ainda é conservadora, omissa, repressora, não há abertura para ver, ouvir e compreender os estudantes que fogem à heterossexualidade, não possibilitando a visibilidade da homossexualidade. Ainda que desejando a visibilidade e participação em discussões que envolvem essa temática, muitos dos sujeitos veem a escola como não preparada para a abordagem da homossexualidade. Embora haja pessoas a quem a temática "pode e deve! [ser trabalhada] mas por homossexuais...somente um homossexual pode mostrar q ser gay eh normal...eh mostrando que se faz algo...não falando...". O que me parece equivocado, afinal a temática da homossexualidade não está apenas relacionada aos homossexuais. Das reivindicações e lutas por libertação que envolvam sujeitos homossexuais, devem estar também participando os heterossexuais, a questão não envolve apenas uma parcela da população, envolve a todos, visto que todos fazem parte da sociedade, que nela estão inseridos e que reciprocamente participam da construção histórica e cultural de identidades sociais, de gênero e sexuais.

\section{Considerações Finais}

Paulo Freire (1987), em Pedagogia do Oprimido, lembra-nos que calar os oprimidos e tirar deles o direito à fala é tirar do próprio opressor o direito de se libertar, o direito de enxergar-se opressor, o direito a usar as palavras em prol de si mesmo.

Ainda que haja alguma visibilidade a respeito da homossexualidade, sua repercussão varia de acordo com o sentido atribuído a ela. O movimento gay, os organismos nacionais e internacionais que lutam em prol de direitos humanos e, mais precisamente, de direitos sexuais têm contribuído para dar visibilidade social e aprimorar políticas e programas contra violências em relação a homossexuais. Entretanto, a visibilidade e a invisibilidade ainda têm resultado em sofrimentos; os preconceitos sociais, negações e exclusões revelam violências de ordens diversas. A invisibilidade por contrariar o desejo de ser visto, de ser aceito, de participar, de ter um lugar nas relações sociais, sem ter que se esconder, que se negar; a visibilidade pela reação que provoca no outro: reação que nega a possibilidade de satisfação do desejo de 
aceitação, participação, ligado ao próprio desejo de 'ser visto'.

A contribuição deste trabalho se dá a partir do que vivenciaram e falaram os alunos e ex-alunos que assumem uma orientação sexual diferente da heterossexualidade; falas que apontam para as possibilidades de uma escola construída com bases em uma sociedade mais justa, igualitária, solidária nas relações de convivência, plural e democrática nas relações de poder.

Não discutimos, nas escolas, alguns temas que estão presentes em nossos dias e na vida ou família de muitos de nossos alunos, como por exemplo, o fato de que $o$ ato sexual não tem a necessidade de ser vinculado ao casamento e a reprodução, mas sim aos sentimentos, desejos e a avaliação pessoal de cada um. Deixamos de discutir que a sexualidade deve ser vivida e vivenciada em suas variedades e multiplicidades e não com bases em modelo único construído para regularização da sociedade. Educadores deveriam saber quando utilizar as oportunidades que se apresentam e discutir as angústias que foram silenciadas.

O que não deixa de ser perturbador é saber que a maioria dos educadores é do sexo feminino, mulheres que ainda sofrem com as diferenças e as separações sociais, as desvalorizações e a necessidade de reafirmar a capacidade e competência feminina nas várias áreas sociais; essas mesmas mulheres contribuem para a separação e diferença e desigualdade entre os gêneros.

As lutas feministas contribuíram muito para as mudanças, inclusive nos discursos e atitudes discriminatórias que hoje se fazem mais dissimuladas, discretas e que contribuem para que se criem, também, novas formas de resistência. Porém, a escola ignora gays e lésbicas e este ignorar não é ingênuo nem neutro, mas participa (ou é um dos modos) de imposição de uma dada construção de gênero, forçando o jovem a repensar sua orientação sexual e as dificuldades que terá que enfrentar socialmente, mas a dificuldade, muitas vezes, ao contrário do que se espera, fortalece o indivíduo para que possa lutar por um novo lugar social. Ouvimos vários discursos, de educadores e de pesquisadores, que tentam nos fazer acreditar que apenas a informação em relação à sexualidade resolveria o silenciamento ou que os professores não abordam temas polêmicos por não estarem preparados, ou por terem problemas de formação seja inicial ou continuada. Informar-se sobre questões pertinentes como a sexualidade envolve um compromisso que o educador deve assumir por fazer parte da construção de uma sociedade mais justa e menos desigual.

Nesta perspectiva, o professor, no contexto da sala de aula, pode promover a percepção positiva das diferenças, desmistificando estigmas, proporcionando um convívio de mútuo respeito e apoio entre os alunos. O professor deve saber que a elaboração consciente da orientação sexual, por parte do adolescente, permite a este enfrentar emocionalmente mais confiante as representações sociais negativas sobre sua sexualidade e imagem.

A escola poderia quebrar parte do silêncio por meio de discussões sobre a forma como revistas, jornais, meios de comunicação, livros, filmes utilizados pelos alunos trazem temas como a afetividadelsexualidade. Se a escola assim o fizesse estaria legitimando o que já circula entre os jovens, estaria dando vozes ao que já é visto e lido por eles, estaria oportunizando a valorização dos vários modos de vivenciar a sexualidade e os modos de vida que diferenciam do único modelo.

$1 \quad$ Karl Maria Benkert (1824-1882) usava também os nomes Karl Maria Kertbeny e Károly Maria Kertbeny, sendo este último o mais conhecido. Foi escritor, jornalista e tradutor; nascido em Viena, lutou, juntamente com o seu contemporâneo Karl Ulrichs - primeiro escritor e jornalista militante dos direitos gays a se autodenominar publicamente como um homossexual - contra o encarceramento dos homens que mantinham relações sexuais com outros homens. Assim como Ulrichs, Kertbeny acreditava que se a homossexualidade fosse reconhecida como algo inato e não como falha moral, a justiça não mais prenderia e executaria os homossexuais. Para maiores detalhes ver Feray, Jean-Claude and Herzer, Manfred, 1990. 'Homosexual Studies and Politics in the 19th Century: Karl Maria Kertbeny'. Journal of Homosexuality Vol. 19 no. 1.

2 Marta Suplicy, Antonio Carlos Egypto, Francisca Vieitas Vergueiro, Maria Aparecida Barbirato, Maria Cecília Pereira da Silva, Cecília Simonetti e Jacques Schwarzstein, em março de 1994, através do GTPOS, ECOS, ABIA e Casa do

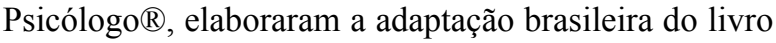
'Guidelines for Comprehensive Sexuality Education, Kindergarten - 12th Grade', de 1991, publicado originalmente nos Estados Unidos.

3 Os Parâmetros Curriculares Nacionais $\left(1^{\mathrm{a}}\right.$ a $4^{\mathrm{a}}$ séries) trazem, no volume 10 , Pluralidade Cultural e Orientação Sexual; os que são direcionados para o terceiro e quarto ciclos do ensino fundamental $\left(5^{\mathrm{a}}\right.$ a $8^{\mathrm{a}}$

Patricia Magri Granúzzio 
séries) trazem em um único volume os temas transversais a serem abordados, ou seja, ética, pluralidade cultural, meio ambiente, saúde, orientação sexual, trabalho e consumo.

\section{Referências}

ABRAMOVAY, Miriam; RUA, Maria das Graças. Violência nas Escolas. $4^{\mathrm{a}}$ ed. Ed. Unesco, Inst. Ayrton Senna, UNAIDS, Banco Mundial, 2002.

ABRAMOWICZ, Anete; SILVÉRIO, Valter Roberto (Orgs). Afirmando Diferenças: montando o quebra cabeça da diversidade na escola. Campinas, SP: Papirus, 2005.

ALTMANN, Helena. Orientação Sexual nos Parâmetros Curriculares Nacionais. Revista de Estudos Feministas, ano 9, n. 2, p. 575 - 585, 2001.

BAKHTIN, Mikhail. Marxismo e filosofia da linguagem. São Paulo: Hucitec, 1990.

BAPTISTA, Marisa Todescan da Silva. O estudo de identidades individuais e coletivas na constituição da história da psicologia. Memorandum: memória e história em psicologia, n. 2, p. 31 - 38, 2002. [Disponível em $<$ http://www.fafich.ufmg.br/ memorandum/artigos02/b aptista01.htm $>$ ]

BAUMAN, Zygmunt. Identidade: entrevista a Benedetto Vecchi. Rio de Janeiro: Jorge Zahar Ed., 2005.

BRASIL. Secretaria de Educação Fundamental. Parâmetros curriculares nacionais: História. Brasília: MEC/SEF, 1998.

Parâmetros curriculares nacionais: terceiro e quarto ciclos: apresentação dos temas transversais. Brasília: MEC/SEF, 1998.

Parâmetros curriculares nacionais: pluralidade cultural, orientação sexual. Brasília: MEC/SEF, 1997.

BRITZMAN, Deborah P. O que é Esta Coisa Chamada Amor. Identidade Homossexual e Currículo. Educação e Realidade, v. 21, n. 1, p. 71 - 93, 1996.

Curiosidade, sexualidade e currículo. In:
LOURO, Guacira Lopes (org.). O corpo educado: pedagogias da sexualidade. Belo Horizonte, MG: Autêntica, 2001, p. $83-112$.

CAMARGO, Ana Maria Faccioli de; RIBEIRO, Claudia. Sexualidade(s) e Infância(s): a sexualidade como um tema transversal. São Paulo: Moderna, 1999.

CASTRO, Mary; ABRAMOVAY, Miriam; BERNADETE, Lorena. Juventude e Sexualidade, Brasília: UNESCO, 2004.

CID-10 - Classificação Estatística Internacional de Doenças e Problemas Relacionados à Saúde - Décima Revisão, Volume I - Centro Colaborador da OMS para a Classificação de Doenças em Português (Centro Brasileiro de Classificação de Doenças) - Faculdade de Saúde Pública da Universidade de São Paulo/Organização Mundial de Saúde/Organização Pan-Americana de Saúde. Implementação para disseminação eletrônica efetuada pelo DATASUS Departamento de Informática do SUS, Secretaria Executiva, Ministério da Saúde. [Disponível em http://www.datasus.gov.br/cid10/webhelp/cid10.htm]

CORTEZ, Marília Cecília; SOUZA, Cristiano de. Sexo é uma coisa natural? A contribuição da Psicanálise para o debate sexualidade/escola. In: GROPPA AQUINO, Julio (Org.). Sexualidade na escola: alternativas teóricas e práticas. São Paulo: Summus Ed., 1997. p. 11-24.

CRUZ, Maria Nazaré da. Palavras e gestos no jogo interativo: um estudo dos processo de significação no cotidiano de um berçário de creche. Campinas, São Paulo, 1995. Dissertação (mestrado) Universidade Estadual de Campinas, Faculdade de Educação, São Paulo.

FACCHINI, Regina. Sopa de letrinhas? Movimento homossexual e produção de identidades coletivas nos anos 90. Rio de Janeiro: Garamond, 2005.

FOUCAULT, Michel. História da sexualidade vol. I. Rio de Janeiro: Edições Graal, 1988.

História da sexualidade vol. II. Rio de Janeiro: Edições Graal, 1984.

História da sexualidade vol. III. Rio de Janeiro: Edições Graal, 1985.

Os anormais. São Paulo: Martins 
Fontes, 2001.

FREIRE, Paulo. Pedagogia do Oprimido. Rio de Janeiro: Paz e Terra, 1987.

Pedagogia da Autonomia - Saberes

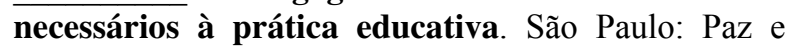
Terra, 1997.

FRY, Peter. Para Inglês Ver: Identidade e Política na Cultura Brasileira. Rio de Janeiro: Zahar, 1982.

FRY, Peter; MACRAE, Edward. O que é homossexualidade. São Paulo: Brasiliense, 1985.

HELMINIAK, Daniel A. O que a Bíblia realmente diz sobre a homossexualidade. São Paulo: Summus, 1998.

LODI, Ana Claudia. A leitura em segunda língua: práticas de linguagem constitutivas da(s) subjetividade(s) de um grupo de surdos adultos. Caderno CEDES, v. 26. n. 69, Campinas: Maio\Agosto 2006.

LOURO, Guacira Lopes. Gênero, sexualidade e educação: Uma perspectiva pós-estruturalista. Petrópolis, RJ: Vozes, 1997.

Segredos e mentiras do currículo: $\overline{\text { sexualidade }}$ gênero nas práticas escolares. In: SILVA, Luis Heron (Org.). A escola cidadã no contexto da globalização. Petrópolis:Vozes, 2000, p. 33 - 47.

O corpo educado: pedagogias da

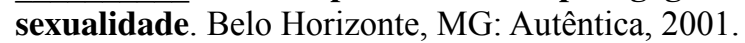

Gênero: questões para a educação. In: BRUSCHINI, Cristina; MACRAE, Edward. A construção da igualdade: identidade sexual e política no Brasil da abertura. Campinas: Editora da UNICAMP, 1990, p. 225 - 242.

MACRAE, Edward. Em defesa do gueto. In: GREEN, James N; TRINDADE, Ronaldo (Orgs.). Homossexualismo em São Paulo e outros escritos. São Paulo: Ed. Unesp, 2005, p. 291 - 308.

MASTERS, William H.; JOHNSON, Virginia E. Homossexualidade em Perspectiva. Editora Artes Médicas, 1979.

MEDRADO, Benedito; SPINK, Mary Jane P. Produção de sentidos no cotidiano: uma abordagem teórico-metodológica para análise das práticas discursivas. In: SPINK, Mary Jane P. Práticas discursivas e produção de sentidos no cotidiano: aproximações teóricas e metodológicas. 2.ed, São Paulo: Cortez, 2000, p. $41-62$.

MISKOLCI, Richard. Um corpo estranho na sala de aula. In: ABRAMOWICZ, Anete; SILVÉRIO, Valter Roberto (Orgs.). Afirmando Diferenças: Montando o quebra-cabeça da diversidade na escola. Campinas, SP: Papirus, 2005a, p. $13-25$.

Vivemos uma Crise das Identidades de Gênero? Texto apresentado no GT "Gênero na Contemporaneidade" na XXIX Reunião Anual da ANPOCS, Caxambu, Minas Gerais, 25 a 29 de out. 2005b.

MOTT, Luiz; CERQUEIRA, Marcelo; ALMEIDA, Cláudio. O crime anti-homossexual no Brasil. Salvador: Editora Grupo Gay da Bahia, 2002.

O lesbianismo no Brasil. Porto Alegre: Mercado Aberto, 1987.

ORAISON, Marc. A Questão Homossexual. Rio de Janeiro: Nova Fronteira, 1997.

VYGOTSKY, Lev S. Pensamento e linguagem. São Paulo: Martins Fontes, 1987.

A formação social da mente: o desenvolvimento dos processos psicológicos superiores. $6^{\mathrm{a}}$ ed. São Paulo, Martins Fontes, 2002.

Recebido em 21 de abril de 2011.

Aceito em 29 de novembro de 2011. 